BULLETIN Bulletin hispanique

HISPANIQUE Université Michel de Montaigne Bordeaux

$114-2 \mid 2012$

Varia

\title{
Los conflictos de memoria en la España post- franquista (1976-2010)
}

entre políticas de la memoria y memorias de la política

Jean-François Macé

\section{OpenEdition}

\section{Journals}

Edición electrónica

URL: https://journals.openedition.org/bulletinhispanique/2150

DOI: 10.4000/bulletinhispanique.2150

ISSN: $1775-3821$

Editor

Presses universitaires de Bordeaux

Edición impresa

Fecha de publicación: 31 diciembre 2012

Paginación: 749-774

ISBN: 978-2-86781-855-4

ISSN: 0007-4640

\section{Referencia electrónica}

Jean-François Macé, «Los conflictos de memoria en la España post-franquista (1976-2010)», Bulletin hispanique [En línea], 114-2 | 2012, Publicado el 05 enero 2016, consultado el 28 julio 2022. URL: http:// journals.openedition.org/bulletinhispanique/2150 ; DOI: https://doi.org/10.4000/bulletinhispanique. 2150

All rights reserved 


\title{
Los conflictos de memoria en la España post- franquista (1976-2010): entre políticas de la memoria y memorias de la politica
}

\author{
Jean-François Macé \\ Université R. Descartes - Paris 5 - La Sorbonne
}

Cet article analyse les conflits de mémoire qui dérivent de la guerre civile et du franquisme depuis la période de la transition démocratique à nos jours en proposant une approche historiographique et sociologique sur la manière dont se sont déployées et articulées politiquement et socialement des interprétations rivales du passé et, de fait, comment ces dernières se sont converties en questions publiques incontournables de l'actuelle démocratie espagnole.

Mots-clés : conflits, mémoire, politiques, post-franquisme.

Este artículo analiza los conflictos de memoria que se derivan de la guerra civil y del franquismo desde el periodo de la transición democrática a nuestros días proponiendo un acercamiento historiográfico y sociológico a cómo se desplegaron y se articularon politicamente y socialmente interpretaciones rivales del pasado y, por tanto, cómo se han convertido en cuestiones publicas ineludibles de la actual democracia española.

Palabras claves: conflictos, memoria, políticas, post-franquismo.

This paper aims to analyse the conflicts of memory originating in the Spanish Civil War and Franco's regime, from the period of the transition to democracy till our days, by proposing, under historiography and sociology approach, a study of the way these two antagonistic interpretations of the past became to be politically and socially accepted. We will also analyse how this issue has become an inescapable point in today's Spanish democracy.

Keywords: conflicts, Memory, Politics, Post-franquism period.

\footnotetext{
* Abreviaturas:

ETA: Euskadi Ta Askatasuna

ARMH: Asociación para la Recuperación de la Memoria Histórica

ONU: Organización Naciones Unidas

PP: Partido Popular

ICV: Iniciativa Cataluña Verdes

PSOE: Partido Socialista Obrero Español
}

CiU: Convergència Democràtica de Catalunya i Unió Democràtica de Catalunya

BNG: Bloque Nacional Gallego

ERC: Izquierda Republicana Catalán

IU: Izquierda Unida

AES: Alternativa Española

PNV: Partido Nacionalista Vasco 


\section{INTRODUCCIÓN}

Hace veinte ańos, la incertidumbre sobre cómo abordar un asunto tan complejo como la articulación y el impacto político y social de la memoria colectiva de la guerra civil y del franquismo era todavía enorme. Desde entonces, se ha realizado una ingente cantidad de investigaciones académicas sobre las políticas emprendidas y la influencia que pueden tener los recuerdos para lidiar con un pasado tan traumático. Sin embargo, entre la extensa literatura que se ocupa de estas complejas cuestiones, uno de los aspectos que probablemente hasta ahora ha recibido una atención más escasa y que queda particularmente por desarrollar es la conflictividad de la memoria. El trabajo que se presenta a continuación pretende ser una aportación en este sentido y, a través de esta interesante problemática que introduce las confrontaciones de la memoria, contribuir a proporcionar algunos elementos nuevos de comprensión para el análisis histórico y sociológico de las memorias en el proceso de cambio político en España.

Casi cuarenta años han pasado desde el final del régimen de Franco. A priori, ninguno de los cambios políticos fundamentales introducidos en 1939 subsisten en la España de hoy. El poder político emana del pueblo, expresado mediante el sufragio universal y el libre desarrollo de los partidos políticos y los sindicatos de clase. Los derechos humanos son reconocidos y garantizados, y existe una plena libertad de expresión del pensamiento. Sin embargo, sería erróneo creer que cuatro décadas de historia pueden desaparecer sin dejar rastro y que los consensos políticos e institucionales de la transición, que ayudaron a construir una convivencia estable y democrática, así como los silencios resultantes, llegaron milagrosamente a borrar todo recuerdo del pasado. Incluso se puede decir que pocos procesos de cambio político han sido tan influenciados por la memoria y las lecciones asociadas a ella. En este sentido, la interpretación de ese pasado depende tanto de la dosis de inclinación de los actores políticos a realizar actos que expresen la diferencia moral entre democracia y dictadura, como de las respuestas de las memorias sociales que irrumpen en la conciencia nacional, y se sitúa en la confluencia de dos enfoques del pasado que conviene concertar con el fin de aclarar las formas de interacción y de confrontación entre los actores, así como los modos de articulación y de tensión que afectan el sentido de sus acciones. En este propósito, Paloma Aguilar Fernández habla de una interacción entre las políticas de la memoria, es decir, un conjunto de iniciativas de carácter público que tratan de defender o reforzar una interpretación particular de algunos eventos del pasado muy significativos para determinados grupos sociales o políticos, y memorias de la política refiriéndose a los receptores habituales de estas políticas de la memoria ${ }^{1}$,

1. Paloma Aguilar Fernández, Políticas de la memoria y memorias de la política, Madrid, Alianza Editorial, 2008. 
que otros investigadores han llamado la "audiencia»². Es así, a través de espacios de luchas políticas en las que debaten memorias rivales, como este estudio se propone interpretar la evolución y las dinámicas de los conflictos de memoria del post-franquismo.

\section{UNA TRANSICIÓN ENTRE CONSENSOS Y SILENCIO}

En la teoría, una transición política es un intervalo de tiempo durante el cual se lleva a cabo un conjunto de ajustes institucionales y prácticas sociales, un paso de un poder discrecional definido y controlado por la represión a otro acuerdo en el que la definición y el funcionamiento de las estructuras se someten al debate y a la negativa de los ciudadanos. Se trata de un proceso de «deslegitimación» y "desestabilización»" donde se presentan instituciones y conceptos democráticos que tienden a legitimarse y hacerse valer plenamente frente a instituciones y prácticas autoritarias. En este sentido, este proceso de cambio afecta inevitablemente a las representaciones colectivas que participan en la eliminación de un orden anterior para volver a crear uno nuevo. Sin embargo, cualquier proceso de cambio tiene sus ambigüedades y si la transición es un momento fundacional para la expresión y la ritualización de la memoria colectiva, es también un tiempo en el desenfoque de las definiciones del pasado y futuro. Es una fase que hace referencia a alternativas múltiples e inciertas y en el que la nueva sociedad aún no está completamente perfilada, un momento donde se presentan a la vez elementos de "pre-institucionalización» y de «desinstitucionalización» ${ }^{4}$, un periodo en que el régimen autoritario pierde sus características sin adquirir todavía completamente las del nuevo régimen, una interacción en la cual están presentes memorias y orientaciones normativas, estilos de acción y valores heterogéneos.

A la muerte de Franco, la construcción de la democracia parece ser la aspiración de la inmensa mayoría de los españoles, pero representa también un desafío político y memorial debido a los diferentes actores involucrados y la urgencia de los problemas a resolver: la naturaleza del régimen y las instituciones, el papel de las fuerzas armadas, etc. Las divisiones institucionales, así como los recuerdos de la guerra civil y la represión franquista durante los seis primeros años de democracia, dan lugar a una serie de pactos entre las elites democráticas civiles y los militares cuyos símbolos principales son la amnistía de 1977, la Constitución 1978, y el aborto del intento de golpe de estado de 1981. En este contexto, se puede cualificar esta transición de "consensual» porque la democracia actual no es el producto de una ruptura radical con el régimen

2. Walter Kansteiner, «Finding Meaning in Memory: A Methodological Critique of Collective Memory Studies", History and Theory, 2002, vol. 41, n 2, p. 179-197.

3. César Cansino, «Pensar la transición», La Jordana Semanal, México, septiembre 1994, $\mathrm{n}^{\circ} 276$, p. 39-42.

4. Samuel Phillips Huntington, El orden politico en las sociedades en cambio, Buenos-Aires, Paidos, 1990. 
militar anterior. Este ha tratado de regular su autodisolución garantizándose un control mínimo sobre el poder 5 . Las condiciones del cambio han sido formuladas y negociadas antes de la muerte de Franco con actores políticos claves, incluyendo al Rey Juan Carlos, que se convertirán en los protagonistas principales del proceso democrático. La transición se produjo con un alto nivel de cumplimiento formal de las condiciones impuestas por el régimen antes de su fin: el mantenimiento de la unidad española frente a las reivindicaciones independentistas, la auto-disolución de las Cortes y el Movimiento Nacional, y especialmente la ausencia de cualquier proceso judicial contra los militares o miembros de la administración. Por lo tanto, como señaló Alberto Reig Tapia, la transición democrática ha tenido que enfrentarse a problemas muy serios para penetrar en el proceso irreversible de su consolidación ${ }^{6}$. En otras palabras, si la democratización es una aspiración compartida por la mayoría, la clase política sigue considerando a Espańa como una sociedad no reconciliada y todavía marcada por los recuerdos traumáticos de la guerra civil y la represión franquista. Como lo pone de manifiesto un discurso de 1978 del diputado Juan Reventós Carner, este contexto parece ser el origen de un consenso político y de un compromiso ético simbolizado por la ley de amnistía en octubre 1977:

Hoy, pues, los españoles - tanto los de derechas como los de izquierdas - hemos aprendido la sangrienta lección de la última guerra civil, cuando media España creyó que podía salvar a la otra media inmolándola en un combate fratricida. Hoy, pese a las profundas diferencias que nos separan, hemos llegado, justo por eso, a un acuerdo, a un consentimiento del adversario, ya no más enemigo. Por eso la Constitución no es más que la expresión jurídica de un contrato social, de un consenso colectivo con la Constitución, por fin, la guerra ha terminado ${ }^{7}$.

Durante la transición, las elites políticas se han comprometido a una amnistía progresiva y definitiva de los Franquistas y sus colaboradores. Se espera de ella que tenga una función integradora en el sentido durkheimiano del término, es decir, existir juntos. Pero toda la cuestión está en el hecho de saber en qué condiciones se realiza esta amnistía ¿¿De hecho, el clima de violencia en el que la transición se llevó a cabo no es precisamente lo que ha permitido que la memoria del pasado belicoso tienda a evacuarse con tanta fuerza? ¿Y el temor a las peligrosas consecuencias de la radicalización no es lo que va a moderar las demandas de todos los grupos políticos y sociales representativos de esta época? No olvidemos que, tras la autodisolución de las Cortes Franquistas, el 16 de noviembre de 1976, y la legalización del Partido Comunista, el descontento de los más radicales se ha manifestado rápidamente. En 1977, ETA* reanuda sus atentados, y en enero de ese mismo año, en el barrio de Atocha de Madrid, un comando Neo Franquista asesina a cinco abogados y hiere a otros cuatro

5. Donald Share y Scott Mainwaring, «Transiciones vía transacción: la democratización en Brasil y en España", Revista de Estudios Políticos, n 49, Enero-Febrero 1986, p. 87-135.

6. Alberto Reig Tapia, Memoria de la Guerra Civil: los mitos de la tribu, Madrid Alianza, 2000.

7. Discurso de Joan Reventós Carner en el Congreso el 31 de octubre 1978 en una sesión de la Comisión Mixta sobre el Proyecto de Constitución. 
gravemente. Este contexto de ajuste de cuentas con más de 600 asesinatos, y sobre todo el intento fallido de golpe de Estado del 23 de febrero de 1981, tres años después de la aprobación por referéndum de la Constitución, obviamente no son favorables a una revisión política efectiva y a la apertura del debate sobre las acciones represivas de la dictadura. Muy pronto comienzan a aparecer, tanto en la prensa como en los círculos culturales, ciertas declaraciones que, aunque minoritarias, denuncian una ocultación del pasado para consolidar el nuevo régimen democrático y ponen en evidencia la existencia de una articulación de una serie de pactos secretos firmados entre las elites políticas. Los que defienden esta tesis consideran que los pactos políticos limitan las oportunidades de debatir abiertamente sobre el pasado e impiden la adopción de normas de justicia para las víctimas de la dictadura. Estos argumentos anticipan lo que muchos autores han llamado un "pacto de silencio" tratando de demostrar que el recuerdo traumático de la guerra civil ha estado presente durante toda la duración de la transición y ha condicionado la adopción de algunas de las decisiones políticas más importantes de este período ${ }^{8}$. Este enfoque introduce una noción de corresponsabilidad de los antagonistas de la guerra civil bien útil para compartir el entierro tácito de la delicada realidad en la memoria colectiva. ¿Así se hizo para prevenir que tales acontecimientos vinieran a reproducirse? ¿Un debate abierto no hubiera podido lograr el mismo resultado? La cuestión queda sobre la mesa. Pero el «consenso» se convierte rápidamente en una de las palabras claves de la transición, y en particular en el Parlamento. A pesar de las tres décadas que han pasado desde el final de la Guerra Civil y de que alrededor del $63 \%$ de la población no participara directamente en los enfrentamientos, aquella se evoca solamente con el objetivo de relegarla en el olvido de los recuerdos más difíciles y dolorosos, los que podrían reactivar conflictos. Las elites políticas se comprometen a no utilizar ese pasado incompatible con el objetivo de establecer un régimen democrático estable y duradero en España, aferrándose al famoso dicho de que «el adversario» debe sustituir «el enemigo» para poder dialogar y negociar. La Constitución, en su elaboración como en su redacción final constituye el culmen de este proceso y la mejor demostración de la puesta en práctica del "consenso» en las negociaciones. Nunca un texto constitucional había suscitado un acuerdo tan general, a través de un referéndum aprobado por el $87,8 \%$ de los votantes. Debido a que orienta a la gran mayoría de los españoles en la misma dirección, muchos la llaman entonces, la "Constitución de la reconciliación», afirmando que las amarguras de la guerra civil han sido superadas, que las posturas "ganadores-derrotados» de la dictadura, finalmente, se diluyen, y que un nuevo régimen dispuesto a hacer que todos los españoles sean iguales ante la ley, es capaz de abrir el camino. José Vidal Beneyto escribió entonces, en 1981, que «la democracia que gobierna España fue construida sobre las losas que cubren la tumba de la

8. Paloma Aguilar Fernández, Memoria y olvido de la Guerra Civil española, Madrid, Alianza Editorial, 1996, p. 21. 
memoria colectiva» ${ }^{9}$. Este comentario será perfectamente ilustrado, un poco más tarde, por las declaraciones del gobierno socialista de Felipe González, el 19 de julio de 1986, para conmemorar el 50 aniversario de la sublevación militar que desencadenó la guerra civil:

La guerra civil no es un acontecimiento conmemorable, por más que para quienes la vivieron y sufrieron constituyera un episodio determinante en su propia trayectoria biográfica [...] El gobierno quiere honrar y enaltecer la memoria de todos los que, en todo tiempo, contribuyeron con su esfuerzo, y muchos de ellos con su vida, a la defensa de la libertad y de la democracia en España [...] recordar con respeto a quienes, desde posiciones distintas a las de la España democrática, lucharon por una sociedad diferente, a la que también muchos sacrificaron su propia existencia [...] que nunca más, por ninguna razón, por ninguna causa, vuelva el espectro de la guerra y del odio a recorrer nuestro país, a ensombrecer nuestra conciencia y a destruir nuestra libertad. Por todo ello el Gobierno expresa también su deseo de que el 50 aniversario de la guerra civil selle definitivamente la reconciliación de los españoles ${ }^{10}$.

La ambigüedad, las contradicciones y las posiciones reversibles de este comunicado gubernamental son representativas de la visión característica del periodo de consolidación de la democracia, en el cual la cultura política de «consenso" prevaleció. Este discurso enuncia una clara intención de forzar el silencio fomentando una autocensura sobre el pasado opresivo institucional, incluso si permanecen, de forma latente, cicatrices políticas abiertas. El recuerdo belicoso del pasado está presente durante todo el proceso de cambio político siendo precisamente este, el que conduce a la ambigüedad que permite a la rama más conservadora influir. Las elites franquistas aceptaron la transición a la democracia a cambio de una amnistía política de hecho basada en el silencio oficial sobre los acontecimientos históricos. Nadie será llamado a rendir cuentas ante la justicia y no se nombró una Comisión, como en otros países, para establecer formalmente los hechos históricos. Ni los «vencidos» de la Guerra Civil ni las víctimas de la dictadura serán rehabilitados simbólicamente, y las fuerzas políticas de la joven democracia evitarán cada vez que sea posible aprobar una condena oficial de la dictadura ${ }^{11}$. En otras palabras, a cambio de reformas profundas y del marco institucional que rige actualmente el país, numerosas cuestiones ligadas al pasado han sido cuidadosamente excluidas del debate político. Pero sólo por un tiempo, porque en realidad, estas medidas políticas no pueden impedir que una memoria popular se mantenga activa. Frente al silencio oficial algunas voces reivindican una rememoración permanente del pasado y denuncian regularmente una reconciliación «manipulada», pidiendo así no solamente un reconocimiento de la verdad histórica, sino también que sus derechos sean reconocidos, y más concretamente, poder defenderse

9. José Vidal Beneyto, Diario de una ocasión perdida: materiales para un principio, editorial Kairos, Barcelona, 1981, p. 33.

10. Presidencia del Gobierno, «Comunicado de prensa», El País, el 19 de julio de 1986, p. 17

11. Sin embargo, según las encuestas del Instituto de Opinión Publica publicadas en 1975 y 1976, el valor político de la "paz» no es mucho superior a la de la «libertad» y la «justicia». 
de las ofensas que el franquismo les infirió. Sin embargo, hace falta esperar a los ańos 90 para ver aparecer las primeras organizaciones memoriales, la más emblemática y activa, sin duda alguna, la Asociación para la Recuperación de la Memoria Histórica.

\section{La Asociación para la Recuperación de la Memoria Histórica}

Sesenta años después de los primeros crímenes de la Guerra Civil, un movimiento asociativo, la ARMH*, ve el día para reivindicar una «recuperación de la memoria histórica» exigiendo que sean exhumadas las fosas comunes donde reposan en masa los restos no identificados de sus familiares. Más allá del tiempo transcurrido desde los dramáticos acontecimientos y de la percepción compartida de una democracia estable, los expertos sugieren diferentes variables a este fenómeno: un sentido de urgencia entre los supervivientes, el relevo de una memoria generacional, etc. En los hechos, la ARMH pide al mismo tiempo el establecimiento de la verdad histórica y un entierro digno para que los mayores y las familias puedan hacer, por fin, su duelo. Este colectivo estima que la dictadura ha hecho desaparecer en sus primeros años al menos 30.000 cuerpos. Entre 1936 y 1939, sabemos con certeza por fuentes históricas que entre 40.000 y 60.000 republicanos fueron asesinados o ejecutados, y que muchos terminaron exhumados por el gobierno de Franco posteriormente a la guerra volviendo sus restos a las familias. Pero para muchas, 70 años después, los cuerpos permanecen en paradero desconocido que la ARHM se propone encontrar vía investigaciones y testimonios.

El 28 de octubre de 2000, la asociación lleva a cabo su primera exhumación utilizando las últimas técnicas arqueológicas, forenses y las pruebas genéticas. Los restos humanos encontrados en una fosa común a la entrada de la pequeña localidad Leonesa de Priaranza del Bierzo permiten identificar el cuerpo de Emilio Silva Faba, un republicano asesinado junto a doce hombres por un grupo de falangistas el 16 de octubre de 1936, y abuelo de uno de los fundadores de la $\mathrm{ARHM}^{12}$. Inmediatamente reivindicaciones de familiares afluyen en toda la península y varias secciones regionales son creadas en Asturias, Extremadura, Cataluña, Andalucía, Galicia, etc. La ARMH se apoya entonces sobre el trabajo de voluntarios y las contribuciones de las familias. Su primer objetivo es tratar de resolver el trauma que el franquismo ha causado a las familias de desaparecidos estigmatizándolas y excluyéndolas de la esfera social. Durante la dictadura, la represión ha restringido cualquier reconocimiento de los muertos republicanos, limitando a sus cercanos la posibilidad de una materialización de la pérdida, y por lo tanto de un duelo asumido. Según el antropólogo Ignacio Fernández de Mata, esta singularidad histórica surge no solamente a raíz del largo tiempo que transcurre entre el asesinato y la exhumación más adelante, sino también por la

12. Emilio Silva y Santiago Macías, Las fosas de Franco, Madrid, Temas de Hoy, 2003. 
larga duración de la dictadura: "Casi cuarenta años de represión y hegemonía ideológica, de subordinación de los vencidos y las víctimas, de somatización del miedo" ${ }^{13}$. Recordemos que el régimen franquista no ocultaba solamente la ubicación de las fosas comunes, sino que también prohibía las visitas a los cementerios, los depósitos de flores en los monumentos, y, a veces vestirse de negro, evitando así que las viudas y familiares de las víctimas pudieran hacer su duelo públicamente. Con la búsqueda de las fosas comunes, las exhumaciones y el análisis de los huesos, testigos de una historia muy violenta, la ARMH da una nueva oportunidad a las familias y rompe con el viejo mito de las «dos Españas» de Franco basado sobre la idea del buen español «católico» y del malo «rojo» sanguinario. Por lo tanto, mediante esta movilización a gran escala de las familias de los muertos o condenados por tribunales militares, de los «nińos de la guerra» evacuados en el extranjero, de los ex presos políticos y trabajadores forzados, y de los descendientes del exilio que perdieron su nacionalidad de origen, la memoria de la Guerra Civil vuelve a ocupar un sitio importante en el debate público. A los que sugieren que el tema ha adquirido una importancia desproporcionada en ese debate, los miembros de la asociación responden que el impacto de las tumbas del franquismo es grande porque la represión lo fue igualmente. De hecho, muchas familias siguen buscando los cuerpos de sus familiares. La ocultación de los muertos en fosas comunes, el uso ideológico de ellos bajo la dictadura, y el silencio oficial impuesto por los consensos políticos de la transición, impidió a los familiares ejecutar públicamente, hasta ahora, los rituales y los homenajes necesarios a la realización del duelo. Estos factores explican en parte por qué la ARMH fue creada por los nietos de las víctimas. La razón principal de la aparición tardía de este tipo de asociación en el ámbito público español puede atribuirse también a la falta de libertades individuales, políticas y civiles durante la larga dictadura de Franco $^{14}$ y al bajo nivel de institucionalización política que se reflejan en la capacidad organizativa de la sociedad civil hasta el fin de los ańos $80^{15}$. Esta distancia temporal es aún más significativa si se considera que, durante la transición, los ayuntamientos donde la represión fue más dura, recibieron una avalancha de quejas de familias deseando registrar la muerte de sus desaparecidos, buscando en este gesto un poco de recuerdo y dignidad, sin que hubiera respuesta satisfactoria. En este sentido, la asociación considera que tiene vocación a liberar un tabú social monopolizado hasta ahora por el Estado.

13. Ismael Fernández De Mata, «La memoria y la escucha, la ruptura del mundo y el conflicto de memorias", Hispania Nova, n 6, 2006.

14. Juan José Linz, The Transition from Authoritarian Regimes to Democratic Political Systems and the Problems of Consolidation of Political Democracy, Yale University Press, 1971, p. 209.

15. Peter McDonough, Samuel Barnes y Antonio Lopez Pina, The Cultural Dynamics of Democratization in Spain, Cornell University Press, 1998. 


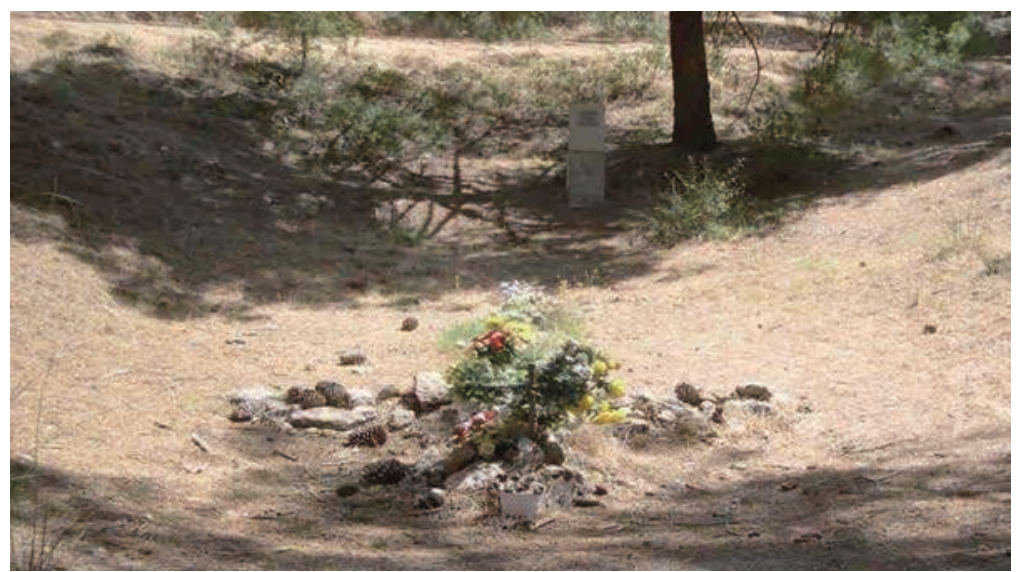

Fig. 1. - Cruz de piedra improvisada en la Fosa común de Viznar, Granada (2007).

(Foto: Jean-François Macé)

La exhumación de fosas comunes no es ni un fenómeno nuevo ni una iniciativa nacida de la movilización de la Asociación para la Recuperación de la Memoria Histórica. La primera apertura de una fosa común se celebró en noviembre de 1971 en Bayubas de Abajo (Soria) mientras particulares realizaron obras que revelaron su existencia ${ }^{16}$. Los restos de 16 personas fueron exhumados en presencia de la Guardia Civil ${ }^{17}$. A su vez, el presidente de la ARMH, Emilio Silva, relata que entre 1979 y 1980, se llevaron a cabo varias exhumaciones, pero que el golpe de estado abortado el 23 de febrero de 1981 reactivó el miedo entre la población, en particular en las zonas rurales, y su explotación por la clase política cambió el curso de los acontecimientos ${ }^{18}$. A partir de este momento, las pocas exhumaciones que tendrán lugar se harán en la discreción más absoluta y suelen retrasarse por falta de recursos. Aunque algunas autoridades locales han proporcionado ayuda, esta ha sido discrecional y sin el apoyo financiero del Gobierno central. Seis años después de su creación, la ARMH afirma haber llevado a cabo la apertura de un centenar de tumbas en toda Espańa y haber excavado más de novecientos cuerpos sin la contribución financiera del Estado. En estas circunstancias, la labor de la ARMH se convierte también en un espacio de mediación en la gestión del pasado. En los últimos años, el tema de las fosas del franquismo no sólo se ha impuesto en todo el país como un eje mayor de movilización por las familias de desaparecidos pero

16. Francisco Espinosa, «Historia, memoria, olvido: la represión franquista», en Antonio Bedmar González (coord.), Memoria y olvido de la guerra civil y la represión franquista, Córdoba, Publicaciones del Ayuntamiento de Lucena, 2003, p. 101-139

17. Gregorio Herrero Balsa y Antonio Hernández García, La represión en Soria durante la Guerra Civil, Soria, Hernández García (ed.), 1982.

18. Emilio Silva y Santiago Macías, op. cit., p. 121. 
también ha invadido el campo de los medios y de la política ${ }^{19}$. La ARMH adquiere interés periódicamente en la prensa nacional y extranjera ${ }^{20}$, así como en las organizaciones internacionales de derechos humanos. Emilio Silva y Santiago Macías, cabezas mediáticas de la asociación, se presentaron ante la $\mathrm{ONU}^{*}$ en 2002 para exigir más medios para las exhumaciones de fosas comunes del franquismo. Sobre la base de la «Declaración de protección de todas las personas contra las desapariciones forzadas» de 1992, que España había firmado, la asociación reunió 64 registros a fín de solicitar que las autoridades nacionales participaran económicamente en las exhumaciones ${ }^{21}$. El «Grupo de Trabajo sobre las Desapariciones» de la ONU reunido en Ginebra en noviembre de 2002 denuncia finalmente el uso de las desapariciones como método de persecución política durante el franquismo y propone intervenir junto al gobierno español en tres casos considerando no tener competencia sobre los que son anteriores a su creación en 1945. El impacto de este recurso fue decisivo en el plan interno y abrió un verdadero debate parlamentario que sería desarrollado por los partidos de izquierda en la oposición a favor de una justicia retroactiva. Organizaciones de defensa de los derechos humanos como Amnistía Internacional España presionan también al gobierno, declarando que una de sus prioridades es ahora "poner fin al silencio, la injusticia, y a una deuda pendiente con las víctimas de la Guerra Civil española y el franquismo» ${ }^{22}$.

La redes sociales de la ARMH se encuentran en toda España pero también en Francia, México y en otros países de destino para los exiliados, y sigue creciendo especialmente a través de Internet. Ella se ha convertido en una de las mayores áreas de expresión del amplio sector de la población que se identifica como víctima del régimen de Franco, reclamando el legado de los valores republicanos y democráticos, o deseando simplemente denunciar la ilusión de una reconciliación basada en el consenso y el silencio. Aunque este colectivo no tiene realmente vocaciones políticas, ya que incluye miembros de diferentes tendencias, edades y clases sociales, sin embargo, de forma implícita, vuelve a poner en circulación valores e ideologías del pasado que a menudo se muestran muy críticas con los poderes fácticos. Para los miembros de la asociación, el verdadero desafío de hoy es no caer en las trampas del juego político de instrumentalización de la historia ${ }^{23}$. Para lograr este objetivo, el movimiento guarda, en la medida de lo posible, una independencia ideológica, y se niega a estar vinculada directamente a un determinado partido político,

19. Montse Armengou y Ricard Belis, Las fosas del silencio ¿Hay un Holocausto español?, Barcelona, Plaza Janés/ Televisió de Catalunya, 2004.

20. La ARMH ha recibido el premio "Paz y et libertad» del 35 aniversario de la revista "Cambio 16» para su ayuda a las familias republicanas de desaparecidos de la guerra civil.

21. Resolución de Naciones Unidas 47/133.

22. Informe de Amnistía Internacional del 18 de Julio de 2005, p. 78.

23. Entrevista en Bruselas con el presidente de la A.R.M.H, Emilio Silva Barrera, el 10 de septiembre de 2007, que había venido a defender la causa de la asociación en el Parlamento Europeo. 
aunque, en los hechos, no rechaza a veces colaboraciones. En España, existen otros grupos militantes ligados a la memoria de la guerra civil y al franquismo, pero por lo general todos están vinculados a un partido político. Así es por ejemplo el caso del «Foro Por la Memoria» del Partido Comunista Español cuya postura provoca regularmente disputas entre las distintas partes sobre las prioridades a mantener, y reprochan a la ARMH sepultar anarquistas, comunistas, socialistas y republicanos de la década de los años 30 «sin que nada en la lápida pueda recordar sus compromisos ideológicos ${ }^{24}$, es decir, se quejan de que los asesinatos políticos sean tratados como un asunto privado. Respondiendo a esa crítica, a través de diferentes exhumaciones presentadas como ejemplares y bastante publicitadas ${ }^{25}$, la ARMH recuerda que estas últimas dan también lugar a ceremonias colectivas y a la colocación de lápidas funerarias en el ámbito público. Por lo tanto, sin someterse a limitaciones ideológicas, y a las divisiones políticas que las acompañan, la ARMH consigue contribuir a la expansión y la gestión de las reclamaciones sobre los efectos de la violencia de la guerra civil y de la dictadura despertando el interés político e institucional. Sin embargo, sus miembros afirman haberse sentido a menudo claramente discriminados, y especialmente en el periodo del gobierno Aznar ${ }^{26}$. En efecto, mientras estaban reclamando desde hacía mucho tiempo asistencia estatal para recuperar a sus muertos, el gobierno Aznar (1996-2004) acordaba la asignación de subvenciones para la creación y el desarrollo de las actividades de la Fundación Francisco Franco.

\section{La Fundación Francisco Franco}

En 2000, bajo el gobierno Aznar del PP*, una subvención anual de 150.000 euros del Ministerio de Cultura es discretamente desbloqueada para la creación y desarrollo de las actividades de la Fundación Francisco Franco oficialmente fundada en 2002 y presidida por la propia hija de Franco, la duquesa Carmen Franco Polo. Su objetivo, según su propia página web, es «difundir el conocimiento de la figura de Francisco Franco en sus dimensiones humana, política y militar, así como de los logros y realizaciones llevadas a cabo por su Régimen", pero también "fomentar la investigación histórica, educativa y cultural sobre la España de aquel tiempo ${ }^{27}$. Para ello, la fundación se organiza en torno a varias actividades. En primer lugar, ciclos de conferencias y seminarios

24. Pedreño José María, Apoyar a la ARMH es enterrar la memoria. In Foro por la Memoria. Foroporlamemoria.info, [En línea]. Foro por la Memoria, 2004 [página consultada el 26 de septiembre de 2007]. Disponible en :

http://www.foroporlamemoria.info/documentos/jmpedreno_23012004.htm

25. Por ejemplo las exhumaciones de Ubrique (Cádiz) efectuadas en abril de 2003 o de Valdedios (Asturias) durante el verano de 2003.

26. Entrevista en Bruselas con el presidente de la A.R.M.H, op. cit.

27. Fundación Nacional Francisco Franco, [en línea], FNFF [página consultada el 3 de Enero de 2006]. Disponibilidad y acceso: http://www.fnff.org 
sobre cuestiones relacionadas con sus objetivos. También cuenta con un boletín trimestral que publica diferentes trabajos que sostienen la importancia de «los intereses generales del presente y el futuro». Añádase a esto, la edición y distribución de libros, y, por supuesto, la emisión de medallas conmemorativas para cada aniversario de la muerte del caudillo. Todas estas actividades se apoyan en gran parte sobre un fondo documental del período 1939-1975, y de otros temas diversos que la fundación ha denominado «las políticas nacionales e internacionales a uso de investigación para los historiadores, profesores, periodistas y estudiantes realizando una tesis doctoral». Estos archivos están informatizados en un $95 \%$, es decir, alrededor de 30000 documentos, más de 157000 fotogramas, y por lo menos 173000 imágenes.

Desde 2002, la Fundación ha autorizado la apertura de sus archivos a cerca de 150 investigadores. Sin embargo, si este número puede dejar pensar que es un espacio fácilmente accesible y abierto a todos, en la práctica, el control de la información es casi total. Por lo tanto, hacer demasiadas preguntas directas crea rápidamente desconfianza y dificulta la obtención de cualquier información. Además, la Fundación rechaza automáticamente el acceso a las personas que no están en posesión del carnet nacional de investigación, lo que restringe el paso a los investigadores autónomos o extranjeros. De hecho, esas limitaciones de la información y la selectividad son por lo menos discutibles si tenemos en cuenta que la fundación está financiada en gran parte con dinero público y que la participación financiera privada proveniente de empresas y particulares necesaria para su desarrollo no excede del $10 \%$. En estas circunstancias, es comprensible que las actividades de la Fundación Franco planteen cuestiones y estén sujetas a debate. En $2002, \mathrm{ICV}^{*}$ es la primera en pedir explicaciones al Ministerio de Cultura sobre las ayudas estatales concedidas a la fundación, pero no obtendrá respuestas. En septiembre de 2003, el Gobierno Aznar rechaza tres proyectos de ley presentados por el $\mathrm{PSOE}^{*}$, el grupo parlamentario catalán $\mathrm{CiU}$ y el $\mathrm{BNG}^{*}$, que se debatieron en la Comisión de cultura del Congreso después de que la ministra Pilar del Castillo asignara 26690 euros más a la fundación Franco, consagrándola así como la segunda entidad privada sin fines lucrativos más financiada del gobierno central. Del lado de las asociaciones de víctimas del Franquismo, las quejas se hacen particularmente oír cuando el Patrimonio Nacional decide abrir gratuitamente las puertas del Valle de los Caídos para permitir a la fundación Franco celebrar varias misas con la coartada de que están enterrados allí los muertos de la guerra civil de ambos bandos. Por lo tanto, se acusa al Gobierno Aznar de financiar un dispositivo político-memorial alrededor de la fundación Francisco Franco.

Hoy día, la acción colectiva más notable de la Fundación Franco es sin duda la conmemoración de la muerte del general Franco, que se celebra en el Valle de los Caídos. Cada año, alrededor del 20 de noviembre, la fundación alquila varios autobuses para transportar a sus fieles desde la capital hasta las ciento veinte hectáreas del Valle de los Caídos. El Panteón donde reposan mártires 
y héroes de la «cruzada $»^{28}$ franquista fue imaginado y dibujado por Franco mismo, a fin de consagrar definitivamente su poder y la memoria de sus aliados en la gloria. Cada año el mismo ritual se repite. El sitio donde la tumba del dictador Francisco Franco y el fundador de la Falange Española, José Antonio Primo de Rivera, se reabre para darles tributo en forma de conmemoración religiosa agrupando generalmente entre 3000 y 4000 seguidores. Al unirse a esta misa que dirige el padre Anselmo Álvarez Navarrete a la cabeza de los 25 monjes benedictinos del monasterio, también en el sitio, no es difícil sorprenderse de un marco tan estereotipado: decenas de familias vestidas a la moda de los años 30; jóvenes con crespones nacionales y botas militares; mujeres con abrigos de visón dando paseos en el interior del monumento; hombres exhibiendo escudos de armas; y ventas a la entrada del monumento de objetos diversos tales como calendarios, libros titulado «Franco, un Ejemplar cristiano», etc.

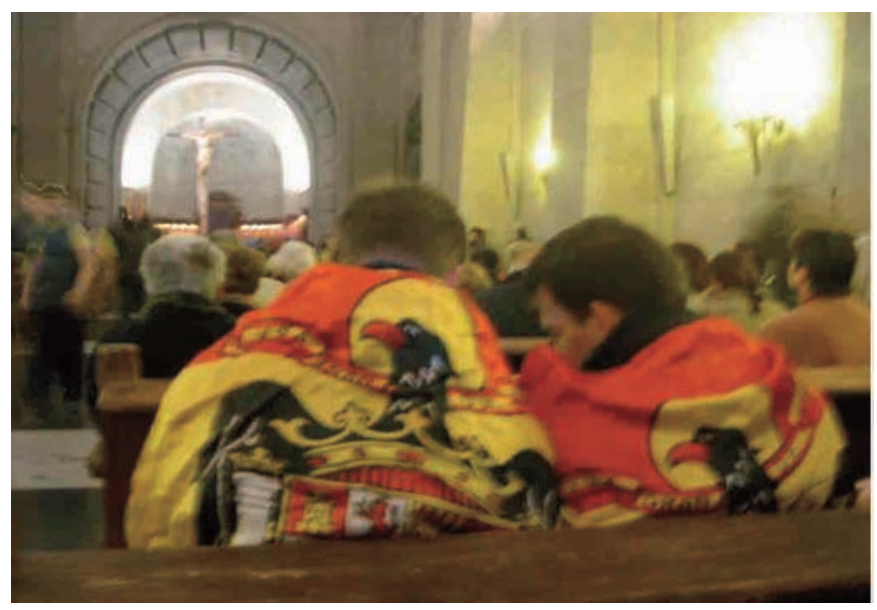

Fig. 2. - Jóvenes arropados de una bandera preconstitucional (2006). (Foto: Jean-François Macé)

A su llegada, los notables se instalan frente al altar de la basílica, en los primeros bancos. Entre ellos están Carmen Franco, la hija del dictador y presidenta de la fundación, el ex coronel que participó en la tentativa golpista de 1981, Antonio Tejero Molina, y Blas Piñar, presidente de la Falange Española. Después del desfile y los saludos de la Juventud falangista delante de la tumba de Primo de Rivera, se celebra una misa en memoria de Franco y sus aliados. Al día siguiente, en Madrid, la celebración se extiende con una concentración en la Plaza de Oriente, con el discurso de Blas Piñar como foco de atención.

28. Palabra utilizada en el preámbulo del decreto de construcción del monumento del 1 de abril de 1940 . 


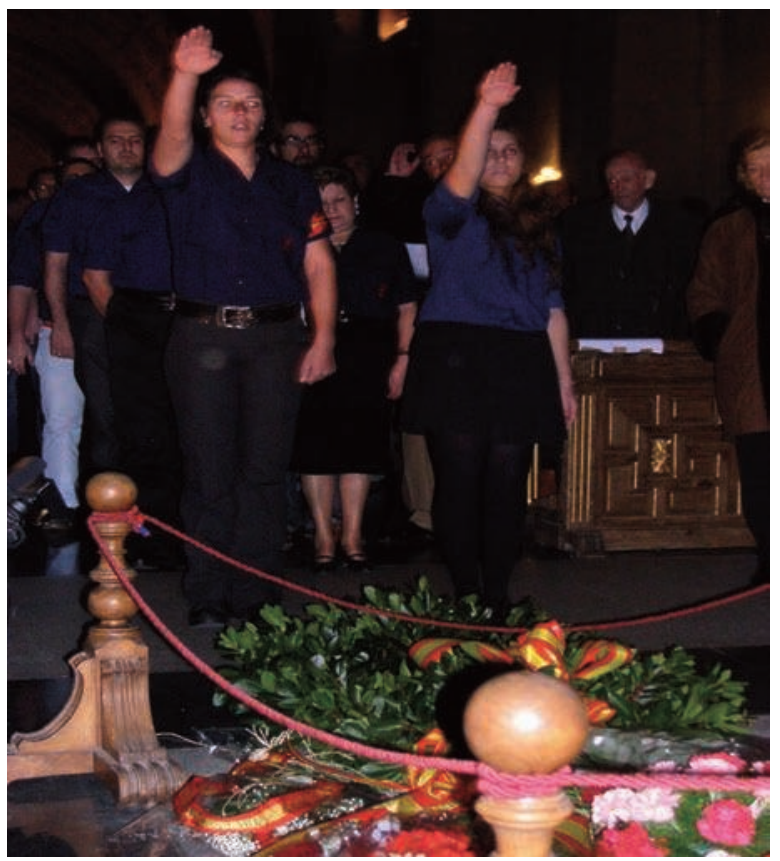

Fig. 3. - Desfile falangista ante la tumba de Primo de Rivera (2006).

(Foto: Jean-François Macé)

Frente a esta conmemoración surge inmediatamente una pregunta: ‘hoy en día, qué representa el Valle de los Caídos? ¿En realidad, se trata de memoria o de algo más? Sin duda, podemos obtener respuestas observando los diferentes oradores, "celebridades», y organizaciones políticas satélites, que, finalmente, en este caso, pueden ser vistos como los portavoces indirectos del movimiento post-franquista en el Estado democrático. La arquitectura y la ceremonia dan importancia al monumento del Valle de los Caídos. Los dos puntos esenciales son su estética y las ceremonias que lo rodean. Pero es también por la presencia y la participación de varios notables y líderes políticos por lo que esta ceremonia toma sentido. Mediante la valorización de la representación política este monumento se convierte en un lugar de intercambio político cargado de símbolos. No hay conmemoraciones sin rituales ni ceremonias, y en este caso, el evento es organizado por la Fundación Franco financiada en gran parte por el Ministerio de Cultura que llega así a convertirse en una caja de resonancia de la red de poder de esta fundación. Por tanto, la Fundación Francisco Franco es también un lugar de interactividad y de valorización política no sólo para los partidos de extrema derecha, sino también indirectamente para el Partido Popular de Aznar, ya que se financia en gran parte por las subvenciones estatales concedidas por su gobierno. Si es cierto que nunca hubo ningún representante del gobierno Aznar, incluido del PP, oficialmente presente en la Fundación Francisco Franco o en sus actividades conmemorativas, sin embargo, la financiación pública concedida por él resulta dar cierta legitimidad oficial a la 
ceremonia del aniversario de la muerte de Franco, e indirectamente, al mismo tiempo, al Presidente Aznar y su partido. Podemos entonces hablar de una forma de sacralización del poder. En efecto, si para Franco el monumento del Valle de los Caídos era una manera de afirmar su poder, bajo el gobierno Aznar, la financiación de la fundación Franco y la autorización cada 20 de noviembre por parte del Patrimonio Nacional al libre acceso al lugar aparecen simbólicamente como un gesto político y una forma de transmitir un mensaje. Recordemos que el PP nació de las cenizas del régimen de Franco, y que su principal fundador, Manuel Fraga, fue ministro de Franco y a la muerte de este, en 1976, lideró junto a otros ex ministros de la dictadura Alianza Popular. En 1989, Alianza Popular deja de existir reagrupándose con el Partido Liberal y convirtiéndose en la rama más conservadora de un nuevo partido político, el PP. Este hecho en sí mismo revela el interés político y memorial que el PP, a través del gobierno, puede tener para financiar las actividades de la Fundación Franco. En primer lugar, los más fuertes partidarios de Franco suelen reunirse en torno a esta fundación y, según las últimas encuestas oficiales, siguen representando por lo menos 60000 votos. Según las propias declaraciones de uno de los líderes de la extrema derecha española, Ricardo Sáenz de Ynestrillas, en el canal de televisión por Internet «Libertad Digital TV», habría en España casi dos millones de simpatizantes de grupos franquistas que forman la base electoral del $\mathrm{PP}^{29}$. En segundo lugar, aunque resulta difícil averiguar la exactitud de estas cifras, y aunque esta proporción de nostálgicos del franquismo sigue siendo baja y minoritaria, aparece que al menos un $10 \%$ de los españoles piensa que el franquismo fue un periodo muy positivo para Espańa, un $46 \%$ cree que era tan positivo como negativo, y sólo un $37 \%$ lo califica como negativo. El 7 \% restante no se pronuncia ${ }^{30}$. Por tanto, si es verdad que el Patrimonio Nacional ofrece el acceso de pago (excepto en el aniversario de la muerte de Franco) a las 430.000 personas que vienen a visitar el monumento, y el $90 \%$ son turistas curiosos por descubrir un templo del totalitarismo que ha sobrevivido a una transición democrática, para otros, la imagen de Franco sigue siendo una referencia ideológica importante. Además de la fundación Francisco Franco y la Falange Española, hay cerca de 40 pequeños grupos de ideología Franquista que no reagrupan a más de 1.000 personas cada uno, y generalmente sin «líder» aparente. Los más importantes tienen como actividad la multiplicación de ofertas de páginas web ${ }^{31}$. Algunos proponen, sin embargo, acciones más agresivas que son habitualmente dirigidas hacia los jóvenes. En este caso, sería más exacto hablar de neo-franquismo en lugar de Franquismo, aunque se encuentra en el primero un apego significativo al segundo. Esta tendencia

29. «Libertad Digital TV» se difunde por internet bajo el mando de Federico Jiménez Losantos, periodista de Telemadrid y de la COPE, que invita e interroga regularmente a personalidades de la extrema derecha tales como miembros del grupo falangista Sociedad Cívica dirigido por Blas Piñar.

30. Centro de Investigación Sociológico, Memoria de la guerra civil y del franquismo, UNED, Estudio 2760, 16 de Abril de 2008.

31. La plataforma «Espańa y Libertad» reagrupa 45 entidades y 5000 afiliados. 
se refleja en acciones como las manifestaciones que tuvieron lugar frente al Congreso en 2006, con su ya clásico lema de "España una y no cincuenta y una» lanzado el día que fue aprobado el muy polémico Estatuto catalán fuertemente contestado por el PP. Para la mayoría de estos activistas la imagen de Franco representa la «salvación» de la unidad nacional. Por tanto, el PP moviliza con éxito un electorado sobre temas tradicionalmente conflictivos en España. De hecho, en la misma lógica se han sucedido y establecido, a través de diferentes generaciones, desde el principio del Franquismo hasta nuestros días, fechas de referencia recordando de manera evidente signos externos de la victoria de Franco durante la guerra civil ${ }^{32}$ : el aniversario del comienzo de la guerra civil el 18 de julio 1936; el 17 de abril, «día de la unificación» del régimen de Franco con la Falange, Comunión Tradicionalista y de otros partidos de derecha; el 29 de octubre, "día de los caídos»; el 1 de abril marcando el final de la guerra; y el 1 de octubre, «día del Caudillo», etc. Por supuesto, todas estas fechas han perdido su vitalidad, y los significados del contenido y la imagen de Franco son probablemente algo diferente para nuestra generación, pero todavía siguen celebrándose. A través de estos procesos, existe la adscripción voluntaria de una herencia en la continuidad, pero el peligro es no ver el significado singular de la acción. En los mismos términos, Young habla de la «invención de una tradición $»^{33}$, que en nuestro caso, parece también una operación política. Las conmemoraciones permiten reactualizar las ceremonias y las tradiciones como elementos centrales. Incluso si no están directamente bajo el pulgar del estado, pero sí de los partidos de extrema derecha y de la fundación Franco, sin embargo, siguen siendo oficialmente toleradas. En este sentido, la conmemoración del 20 de noviembre del Valle de los Caídos se convierte en rituales completos que, de un ańo a otro, se repiten a la vista en un gran despliegue de publicidad. De hecho, estas conmemoraciones históricas pretenden fijar en la memoria colectiva hechos que se suponen significativos para la historia española. El riesgo es que el monumento y el ritual se conviertan en un espacio donde todo es aceptable porque cada uno desea creerlo. Por las prácticas repetitivas, estas ceremonias permiten establecer continuidades que, fusionándose con el monumento, propagan la ilusión de una «memoria común». Desde esta perspectiva, un año después del establecimiento de una comisión interministerial sobre la situación de las víctimas del régimen franquista, y bajo la presión de la oposición de izquierda y de las asociaciones de víctimas, el Gobierno socialista de José Luis Rodríguez Zapatero decide actuar, en un primer tiempo, procediendo a la retirada de las ultimas estatuas de Franco que siguen en pie en el territorio nacional.

32. Paloma Aguilar Fernández, op. cit., p. 142.

33. James E. Young, «Écrire le monument: site, mémoire, critique», Annales ESC, mai-juin $1993, n^{\circ} 3$, p. 733 et 736 . 
DESDE LA CREACIÓN DE UNA COMISIÓN SOBRE LA SITUACIÓN DE LAS VÍCTIMAS DEL FRANQUismo HASTA EL DERROCAMIENTO DE LAS ESTATUAS DE FRANCO

Tras las elecciones del 14 de marzo de 2004, el PSOE busca apoyos en la oposición de izquierda para la investidura de Zapatero, y los encuentra junto a ERC, a IU e ICV*. Durante una reunión con los socialistas Alfredo Pérez Rubalcaba y Diego López Garrido, los representantes de estos partidos, Joan Puigcercós i Boixassa, Gaspar Llamazares y Juan Herrera, exigen «cambios de forma y de fondo» en las políticas de la memoria mencionando una necesidad de «recuperar la memoria como el antídoto más efectivo contra el autoritarismo $»^{34}$. Estas reivindicaciones demuestran que la reparación a las víctimas de la guerra civil y del Franquismo es una cuestión clave en la sociedad y el mundo político español. El 23 de julio de 2004, cumpliendo una de las promesas de campaña de Zapatero, el Consejo de Ministros crea una comisión interministerial encabezada por la vicepresidenta María Teresa Fernández de la Vega para reparar y restaurar la dignidad y la memoria de las víctimas de la guerra civil y la dictadura. Durante los dos meses anteriores a la votación para legalizar el decreto, el 10 de septiembre de 2004, una espectacular "batalla" de memorándum sin equivocaciones estalla en las rúbricas necrológicas de los diarios españoles: «Don. X, de 41 años y siete hijos, Arenas de San Juan, asesinado por los "Rojos" del frente popular con 61 Madrileńos el [...] de 1936»; O, «Don. Y, asesinado en la mañana del [...] de 1936 en Valladolid, de 47 ańos, víctima de la represión fascista». Del lado de la derecha, la temática de un Zapatero revanchista es ampliamente difundida. Varios diarios conservadores sostienen que José Luis Rodríguez Zapatero pretende con esta acción ganar la guerra civil. Casi un año después, respondiendo a la treintena de asociaciones de víctimas y a los cientos de personas que compartieron sus ideas con la Comisión, el gobierno decidió, no sin precaución, una primera acción simbólica que provocó la indignación de algunos y los aplausos de otros: el derrocamiento de la estatua del Caudillo cercana al Ministerio de obras públicas. La noche del 16 al 17 de marzo de 2005, la estatua ecuestre del general Franco, inaugurada el 18 de julio 1959, es furtivamente retirada por orden del Gobierno so color de obras públicas a efectuar poco antes de medianoche. Una decena de periodistas informados de la operación se agrupan en la Plaza San Juan de la Cruz para dar cuenta de ello. Con la crepitación de los flashes los primeros curiosos y también descontentos llegan. Un grupo de una docena de personas liderado por una mujer comienza a atacar a los periodistas presentes en voz alta: «¿Pero qué mal ha hecho este hombre? [...] Si no fuera por él, ahora estaríais todos comiendo vuestra mierda».

Mientras otras personas alertadas por los gritos se acercan, los trabajadores empiezan con dificultad a retirar el monumento anclado en su base desde hace casi medio siglo, y la antigua estatua de Franco se resiste a la grúa el tiempo

34. Intervención de Juan Herrera (ICV) en el debate de investidura, el 15 de abril de 2004. 
suficiente para que unos pocos nostálgicos tengan tiempo de notificarlo a una patrulla de la policía municipal que, presumiblemente para evitar incidentes y ahorrar tiempo, decidió pedir a los trabajadores los permisos necesarios para sacar la estatua y ordenó su cese pendiente de la confirmación de su legalidad. Fueron entonces aplaudidos con entusiasmo por algunas personas convencidas de haber frenado lo que ellas consideraban una afrenta. Pero a la llegada de un camión de la policía antidisturbios y de un representante ministerial que proporcionó los documentos necesarios se escucharon tímidos aplausos de los partidarios del derrocamiento en la multitud que alcanza en ese momento un centenar de personas. Durante el desmontaje de la estatua, un grupo canta "Cara al sol». A las dos de la mañana, cuando la estatua sale de su pedestal y se mantiene en el aire antes de ser instalada en una plataforma cubierta con una sábana blanca tal un fantasma de la historia, unos segundos de silencio se instalan. Finalmente parte de la multitud se dispersa entre algunos comentarios sobre la idea de «romper con el poder».

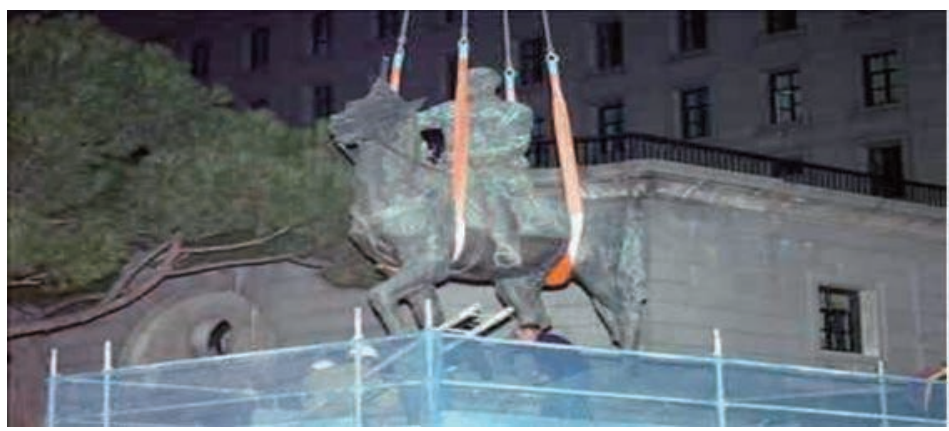

Fig. 4. - Derrocamiento de la estatua de Franco en Madrid (Foto: EFE)

Al día siguiente, un joven neo-franquista permanece inmóvil durante varias horas, el brazo derecho levantado, frente al pedestal vacío. En la capital, varias estatuas de ex ministros socialistas son manchadas de rojo en represalia. El movimiento de extrema derecha AES* lleva ante la Corte Suprema a la Ministra de Fomento, Magdalena Álvarez, por delitos contra el patrimonio artístico y otras prevaricaciones. Por fin, José Utrera Molina, ex ministro del régimen de Franco, hace una declaración bastante explícita unos días después sobre la figura de Franco: «Pese a quien pese, Franco cabalga aún en la historia española. Somos ya minorías los que nos atrevemos a defenderlo, pero estamos dispuestos hasta el último momento de nuestra vida a ser leales» ${ }^{35}$.

Más tarde, otras estatuas del dictador son también retiradas en Guadalajara o en Pobla de Vallbona en la región de Valencia, etc. En las ciudades con una fuerte tradición conservadora quitar las estatuas resulta más difícil. Por lo tanto, si el alcalde de Santander acepta quitar una estatua del dictador,

35. José Utrera Molina, «Aún cabalga», La Razón, el 19 de marzo de 2005, p. 20. 
también decide eliminar un escudo testigo del período democrático de la Segunda República espańola. Probablemente deseaba atenuar las controversias al anunciar que los dos símbolos serían enviados a un nuevo museo dedicado a la historia de la Guerra Civil española de 1936. En Melilla, la estatua se retiró y volvió a remontar en su pedestal en la misma semana como consecuencia de una protesta popular.

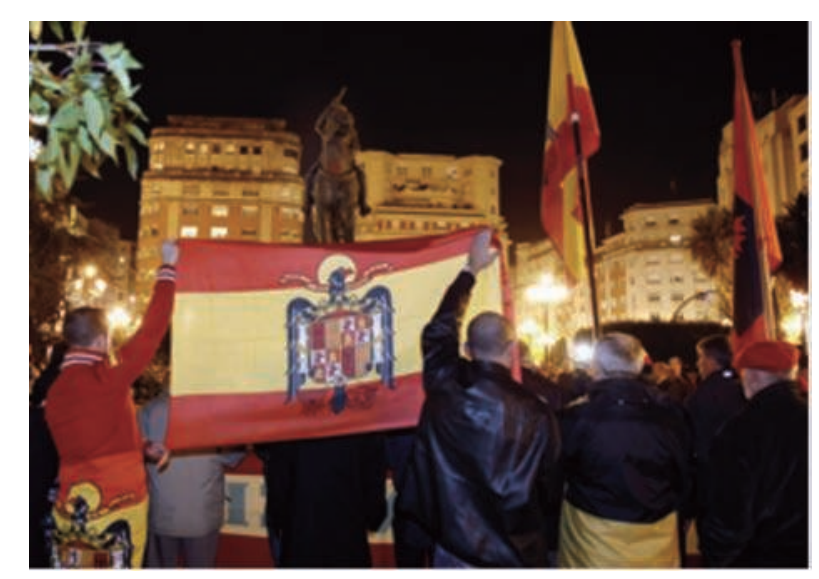

Fig. 5. - Manifestación popular contra la retirada de la estatua de Franco en Santander en la fecha aniversario de su fallecimiento (2007)

(Foto: EFE)

Treinta años después de la muerte del último dictador militar de la Europa occidental, estos episodios pueden sorprender. En primer lugar, mientras que en gran parte del mundo, las estatuas de los dictadores del siglo XX se derrocaron desde hace tiempo, el Gobierno español solo ahora juzga chocante que su país mantenga monumentos a la gloria de un "caudillo» que sumió a Espańa en las décadas más oscuras de su historia moderna. En este sentido, la retirada de las estatuas de Franco en pleno siglo XXI es casi anacrónica y revela claramente la negligencia política de los gobiernos que se han sucedido desde la muerte de Franco frente a la memoria colectiva. Ellos han mantenido durante ańos efigies del ex dictador dejando en evidencia un pasado dolorosamente trágico para millones de españoles. Justo después de la muerte del «Caudillo» hubo algunas destrucciones de monumentos franquistas y algunos municipios cambiaron nombres de calles cuando llegaron al poder en 1979, pero el movimiento se detuvo rápidamente con el temor de que los «viejos fantasmas» llegaran a perturbar el consenso político que se negociaba durante la transición ${ }^{36}$. Por otra parte, parece que la mayoría de los cambios se hizo caso por caso, en función de la mayoría política del lugar, dejando sospechar, por parte de la derecha como

36. En 2006, solamente en Madrid, según mis cálculos, existían todavía 167 calles y monumentos dedicados al «Caudillo» o sus allegados. 
de la izquierda, formas de oportunismo electoral. La elección de los actos y símbolos, como sus modificaciones, no parecen simples coincidencias, y son regularmente objeto de controversias. Es también, sin duda, una manera de tomar posición en los conflictos de memoria para las autoridades políticas. El 18 de julio de 2005, casi un año después de la creación de la comisión para las víctimas de la guerra civil, y a pesar de todas las tensiones, el presidente Zapatero hace una declaración sin precedentes en la historia de la democracia española: «Tenemos que reconocer a las víctimas del régimen franquista porque han sido víctimas de crímenes de una dictadura militar que ha silenciado las libertades durante 40 ańos» ${ }^{37}$. Esta declaración constituye una verdadera ruptura en el mundo social y político de este país, porque desde la muerte del «Caudillo» en 1975, ningún ejecutivo se atrevió a tocar el tema de los "vencidos» de la guerra civil. Según Zapatero, las posiciones del régimen de Franco y la dilación en la llamada "transición» han dado lugar a un retraso evidente en el trabajo de rehabilitación de las víctimas. Con este mismo argumento se propone declarar a 2006 "Año de la Memoria» presentando al Consejo de Ministros un polémico proyecto de ley sobre la rehabilitación de las víctimas de Franco, titulado entonces "Ley de Memoria Histórica», originalmente propuesto por los dos equipos más a la izquierda del Parlamento español, ERC e IU.

\section{La POLÉMiCa LeY «DE MEMORIa HistóRICA»}

El 22 de junio, el Parlamento español proclama a 2006 «Año de la Memoria». El «sí» es votado y apoyado por todos los partidos políticos excepto el PP, que ve en este gesto institucional una «reescritura partidista a favor de los republicanos» ${ }^{38}$. A pesar de este argumento, el 28 de julio de 2006, un proyecto de ley "para la memoria histórica» es aprobado por el Consejo de Ministros. El portavoz del PP en el congreso, Eduardo Zaplana, el día de su aprobación, acusa al presidente Zapatero de querer «dinamitar» la transición y recuperar «la hostilidad de los unos contra los otros» porque, según él, esta ley «no tiene por objetivo ayudar a nadie» sino «tensar, crispar y volver a abrir un debate que nos comprometimos [los españoles] a olvidar» con la aprobación de la Constitución de 1978. En la misma línea que su compañero de partido, para el diputado Ángel Acebes, el presidente Zapatero está «obsesionado con el pasado" y quiere establecer la legitimidad democrática no en 1978 con la Constitución, sino en 1931 cuando fue derrocada la monarquía española de Alfonso XIII y creada la Segunda República Española ${ }^{39}$. Según el PP, con este

37. Cambon Diane. Zapatero embarrassé par sa loi sur le franquisme. In Le Figaro. Le Figaro. fr. [En ligne]. Le Figaro, le 15 octobre 2007. [Page consultée le 20 octobre 2007]. Disponibilité sur :

http://www.lefigaro.fr/international/20060728.FIG000000093_zapatero_embarrasse_par_ sa_loi_sur_le_franquisme.html

38. Escuchado en la «Cadena Ser» el 27 de junio de 2006.

39. Europa Press. El PP acusa a Zapatero de 'olvidar la Transición y rememorar la Guerra 
proyecto de ley, el presidente Zapatero toma el riesgo de afectar seriamente al consenso político e institucional alcanzado por la sociedad española para salir del franquismo debilitando los fundamentos democráticos del sistema actual. En varias ocasiones, el Gobierno socialista trata de dialogar con la oposición de derecha. El diputado socialista Ramón Jáuregui insiste en que la posición del gobierno no está animada por ningún «ardor vengativo» y que tiene solo el objetivo de mirar al pasado «con la libertad y defender la verdad con la valentía de aquellos que asumen también la autocrítica de lo que se hizo mal $»^{40}$. Frente a las protestas del PP que se aferra a su posición y sigue acusando al Gobierno de Zapatero de querer hacer revivir los "fantasmas del pasado», el gobierno ofrece una versión «aseptizada» del proyecto inicial, y en vez de llamarla «Ley para la memoria histórica», acabará titulándola "Ley de extensión de los derechos de las personas afectadas por la guerra civil y la dictadura».

Después de un claro rechazo del PP, de varios meses de debate, y un intercambio de reclamaciones con la oposición de izquierda, el Gobierno propone la elaboración de un texto final que deja a casi todos los grupos descontentos. La formación del PP, las organizaciones de extrema derecha y la Iglesia consideran que la ley mueve un asunto que "ya ha terminado» para los españoles, y conduce a generar nuevas divisiones entre los españoles. Para los partidos de izquierda, primeros promotores del texto, para los nacionalistas moderados, las asociaciones de víctimas de la guerra civil y del franquismo, y las organizaciones de defensa de los derechos humanos, el proyecto final es «insuficiente» para lograr una justa reparación de las víctimas, y por lo tanto «decepcionante». Uno de los puntos discordantes tiene que ver con la revisión de las condenas judiciales. Al principio, invocando la Constitución, el Partido Socialista se niega a que la ley considere la anulación de las sentencias dictadas por los tribunales de Franco que dieron lugar a 50000 condenas a muerte de republicanos españoles y a miles de trabajos forzados. Insistiendo sobre estos hechos, el presidente de IU, Gaspar Llamazares, afirma que «esta ley no tiene ambición y no satisface a nadie», y amenaza con presentar una enmienda a la totalidad del texto si estas disposiciones no se cancelan. Unas doscientas enmiendas sobre este punto han sido presentadas por los diferentes bloques de la oposición.

Incapaces de reunir una mayoría parlamentaria alrededor de este proyecto de ley, los socialistas, que sólo tienen una mayoría relativa, necesitan el apoyo de algunos miembros de la oposición para lograr su aprobación antes de la disolución del Congreso de los Diputados en las elecciones de marzo de 2008. Por lo tanto, el Gobierno decide aplazar la votación de esta ley con el objetivo declarado de llegar a un acuerdo y abrir las negociaciones políticas. En un primero momento, ante la imposibilidad de consenso con la derecha, el

Civil. In El Mundo. El Mundo.es. [En línea]. El Mundo, el 8 de octubre de 2007 [Pagina consultada el 10 de Octubre de 2007]. Disponibilidad en:

http://www.elmundo.es/elmundo/2007/10/08/espana/1191860210.html

40. Escuchado en la «Cadena Ser», op. cit. 
proyecto de ley es reactivado gracias a los acuerdos entre el Partido Socialista y la coalición de IU. De hecho, el gobierno llega a un acuerdo con la oposición de izquierdas que consiste en no anular los juicios sumarios del franquismo, sino en declararlos «injustos» al ser pronunciados por tribunales «ilegítimos». Sin embargo, aunque las sentencias no se anulan, cualquier solicitud de revisión debe ser revisada sin objeción posible de la justicia ${ }^{41}$. El Gobierno se compromete también a dar repuestas a las reivindicaciones económicas y sociales de las víctimas del franquismo dentro y fuera del territorio. Las ayudas a las víctimas del franquismo y a sus familias (pensiones, compensaciones financieras, etc.) son extendidas. En el texto inicial del gobierno, la ley preveía que las familias de "las personas caídas para defender la democracia entre el 1 de enero de 1968 y el 6 de octubre 1977» podían recibir una indemnización de hasta 135.000 euros. Por supuesto, las fechas, las cuantías y las modalidades de ejecución pocas veces se aprobaron con unanimidad. Por lo tanto, la ARMH se muestra perpleja sobre las normas propuestas por el gobierno para gestionar las exhumaciones de las fosas comunes de la guerra civil ${ }^{42}$. Efectivamente, la ley establece que el trabajo de recuperación de cadáveres deberá realizarse a través de la solicitud de descendientes directos de las víctimas o entidades interesadas, pero que «la autorización de las comunidades autónomas correspondientes y de los órganos gubernamentales de entidad local de donde se encuentran los restos» también será requerida. Por lo tanto, la posibilidad de abrir una fosa común no dependerá solo del criterio de un juez como solía hacerse: será imprescindible el visto bueno de la administración autonómica. En otras palabras, la ley del gobierno se presenta como una manera de facilitar las exhumaciones e identificaciones por las diferentes administraciones, pero no asume ninguna responsabilidad. Para el presidente de la ARMH, Emilio Silva, esto equivale a «dejar en las manos de voluntarios las exhumaciones, es decir, las consecuencias de un asesinato» ${ }^{43}$, porque todavía, de las 51 provincias españolas, 20 de ellas aún no han efectuado el censo de los republicanos que murieron durante la guerra civil y la dictadura. Así, Emilio Silva, lamenta que la exhumación se

41. EFE. El «Lute» pide que la Ley de Memoria Histórica anule su proceso franquista. In El Mundo. El Mundo.es. [En línea]. El Mundo, el 4 de septiembre de 2009 [Pagina consultada el 17 de Octubre de 2009]. Disponibilidad en:

http://www.elmundo.es/elmundo/2009/01/03/espana/1230992596.html

42. Junquera Natalia. Desde la bota de Emilio hasta la audiencia Nacional. In El País. El País.es. [En línea]. El País, el 7 de septiembre de 2008 [Pagina consultada el 10 de septiembre de 2008]. Disponibilidad en:

http://www.elpais.com/articulo/espana/bota/Emilio/Audiencia/Nacional/ elpepiesp/20080907elpepinac_6/Tes

Desde entonces, la A.R.M.H recibe una subvención anual del Gobierno de 120000 euros para financiar algunas de sus exhumaciones.

43. Junquera Natalia. El Gobierno deja en manos de la comunidades la apertura de la fosas. In El País. El País.es. [En línea]. El País, el 15 de diciembre de 2008 [Pagina consultada el 18 de diciembre de 2008]. Disponibilidad en:

http://www.elpais.com/articulo/espana/Gobierno/deja/manos/comunidades/apertura/fosas/ elpepuesp/20081215elpepinac_2/Tes 
pueda convertir en «una decisión política de una comunidad autónoma o de otro tipo" y teme que la "marea burocrática" se transforme en una estrategia institucional para evitar cumplir con un proceso memorial que «es urgente». El temor es legítimo porque los supervivientes de los batallones de trabajos forzados que quisieron que fuera reconocido públicamente antes de su muerte el trato que habían sufrido por parte del régimen franquista se enfrentaron a grandes dificultades, especialmente bajo el gobierno Aznar. Aunque algunos presos políticos del Franquismo tenían formalmente la posibilidad de obtener una compensación económica en virtud de la legislación adoptada en 1990 y 1992 por el gobierno socialdemócrata, el PP en el poder desde marzo de 1996 a marzo de 2004 había bloqueado este proceso remitiendo la cuestión de la indemnización a los gobiernos regionales de Espańa donde sus representantes seguían oponiéndose a cualquier iniciativa en esa dirección. Es poco probable que las consideraciones financieras constituyeran el principal obstáculo porque el número de presos políticos de largo tiempo y las personas que sufrieron el trabajo forzado era cada vez menos importante, excepto teniendo en cuenta también los exiliados políticos. Significativamente, uno de los aspectos más llamativos de esta Ley de Memoria Histórica es el resultado de las negociaciones sobre el panel que trata de dar la nacionalidad espańola a los hijos y nietos de los Españoles nacidos en el extranjero tras la huida de sus padres o abuelos durante la guerra civil y la dictadura, y que tuvieron que renunciar a ella entre las fechas del 18 de julio de 1936 al 31 de Diciembre de 1955. La nueva ley les concede la posibilidad de conseguirla si la solicitan desde principios de 2009 hasta finales de 2011. Esto concierne a cientos de miles de personas en Europa y en América Latina. Por último, sin ceder en la cuestión de las fechas para tener derecho a una indemnización que según el Gobierno permite también compensar a las víctimas de los grupos de la extrema izquierda, el límite de indemnización se eleva a 150000 euros. Además, 3000000 de euros serán distribuidos entre la cuarentena de asociaciones de víctimas del franquismo, entre otras la ARMH.

Mientras tanto, en los debates parlamentarios, la ministra de Cultura, Carmen Calvo, avanza sobre un terreno delicado a paso lento por no despertar las susceptibilidades de unos y otros. Mientras que la oposición de derecha sigue acusando a los socialistas de "reabrir viejas heridas» y protestan por la «degradación» de los edificios históricos en referencia al artículo 15 de la Ley, la oposición de izquierda estima incomprensible, por ejemplo, que las inscripciones "Por Dios y Por España» aún sigan presentes sobre las fachadas de muchas iglesias. Sobre esta cuestión el Gobierno encuentra finalmente un arreglo proponiendo suavizar las medidas de principio exigidas por IU y E.R.C. sobre los monumentos de la dictadura. Así, los símbolos franquistas serán retirados únicamente cuando estos exalten a «una parte» de los españoles que participaron en la guerra civil. Como excepción, se encuentran los casos cuyo valor artístico y cultural reclama la conservación. 


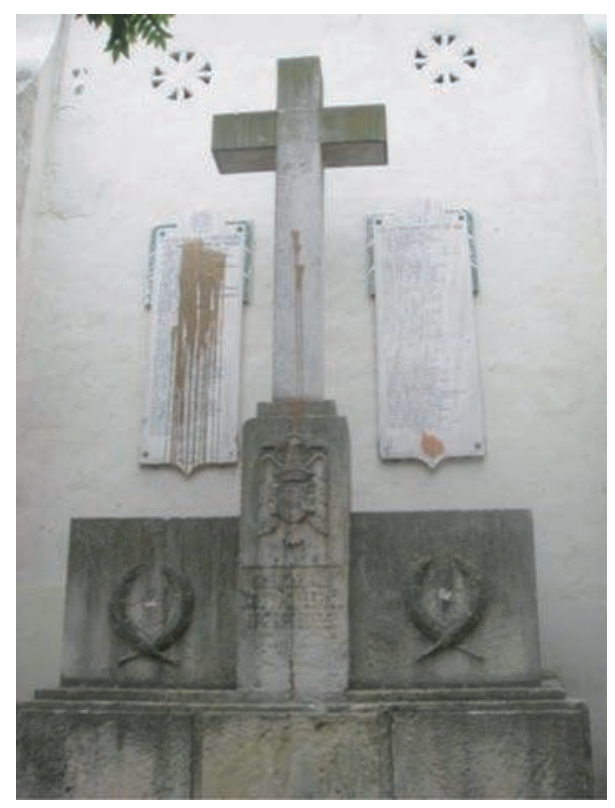

Fig. 6. - Monumento a los caídos «por Dios y Espańa» manchado de rojo en la fachada de la Iglesia de Ciempozuelos, Madrid (2007). Hoy día el monumento sigue en pie y ha sido limpiado. (Foto: Jean-François Macé)

A cambio de ello, junto a la oposición de izquierda, el Gobierno deja entender a las asociaciones franquistas y de extrema derecha su intención de limitar todas las celebraciones y exaltaciones de actos políticos de la guerra civil o de la dictadura obligando a la Fundación Francisco Franco a modificar sus estatutos asociativos ${ }^{44}$. En el caso del Valle de los Caídos, la ley prevé una especie de «despolitización» del lugar mediante la prohibición de actos de naturaleza política exaltando el franquismo. Para ello, el gobierno Zapatero amenaza a la fundación Franco retirarle las ayudas estatales recibidas desde 2000 si estas reglas no se cumplen correctamente. Esta advertencia no es casual, pues en 2005, cuando el Gobierno de Zapatero decidió aplicar al 30 aniversario de la muerte de Franco los horarios de las normas del Patrimonio Histórico en el Valle de los Caídos, y hacer cumplir la prohibición de todos los símbolos preconstitucionales como lo exige la ley española, la misa en memoria de Franco se convirtió en un verdadero enfrentamiento ${ }^{45}$, reabriendo también debates sobre el papel de la Iglesia durante la dictadura. Mientras que las movilizaciones de

44. En el proyecto de ley, el tercer decreto punto dedicado al monumento del Valle de los Caídos establece que la Fundación Franco deberá incluir en sus objetivos la obligación de honrar la memoria de todo los espańoles que cayeron en la guerra civil y la dictadura a fin de reconocer la memoria mas allá de las consideraciones partidistas.

45. EFE. La Guardia Civil impide la entrada al Valle Caídos a un grupo de falangistas. In El Mundo. El Mundo.es. [En línea]. El Mundo, el 17 de noviembre de 2011[Pagina consultada el 23 de noviembre de 2008]. Disponibilidad en:

http://www.elmundo.es/elmundo/2008/11/16/madrid/1226840511.html 
colectivos amplificadas por su cobertura mediática insisten sobre la necesidad urgente de una rehabilitación memorial del compromiso republicano exigiendo que los restos de Franco y José Antonio de Rivera sean desplazados del Museo financiado por todos los españoles con fondos públicos, los demás se posicionan en torno a los valores de la Iglesia Católica defendiendo la idea de que no se debe «obstaculizar la celebración de funerales católicos a quienes murieron por Dios y por España ${ }^{46}$. Significativamente, el 28 de octubre de 2007, tres días antes de la aprobación parlamentaria de la ley, se podía asistir en Roma a la beatificación masiva, la más importante en la historia de la Iglesia, de 498 sacerdotes espańoles, elegidos entre los 10000 que fueron ejecutados por los republicanos durante la guerra civil ${ }^{47}$, accediendo así ellos a la calidad de «bienaventurados». Las asociaciones de víctimas viven entonces este acto como una provocación y exigen a la Iglesia que "perdone y pida perdón ${ }^{48}$. El regreso de tales disensiones incomoda en los debates a los nacionalistas moderados que, debido a su tradición católica, tardan en tomar posición antes de reclamar que la ley sea también explícita en cuanto a los «abusos» cometidos por los republicanos durante la guerra civil. Pero el Gobierno se niega con el motivo de no hacer juicios históricos. Sin embargo, a pesar de todas las concesiones hechas por ambas partes, el Gobierno necesita los votos de los nacionalistas para aprobar la ley antes de las elecciones generales de marzo de 2008. Las negociaciones entre el PSOE, el PNV, el BNG y CiU* culminan finalmente con un acuerdo: la creación de un Centro de Documentación en Salamanca que integre también el Archivo General de la guerra civil. Este acuerdo viene a cerrar un conflicto viejo de 70 ańos entre el gobierno central y los gobiernos nacionalistas y permite que la ley nominada «de extensión de los derechos de las personas afectadas por la guerra civil y la dictadura» sea finalmente aprobada por el Congreso de los Diputados el 31 de octubre 2007.

\section{Conclusión}

Queda claro que en España el camino para asumir el pasado franquista aún es largo. La transición ha permitido la introducción de las instituciones democráticas cuya estabilidad ha sido conseguida, sin embargo la sociedad

46. Europa Press. Una manifestación antifascista en Madrid y una misa en el Valle de los Caídos recordarán hoy el 20-N. In Europa Press. Europapress.es. [En línea]. Europa Press, el 20 de noviembre de 2008 [Pagina consultada el 23 de noviembre de 2008]. Disponibilidad en:

http://www.europapress.es/nacional/noticia-manifestacion-antifascista-madrid-misa-vallecaidos-recordaran-hoy-20-20081120112409.html

47. Estas 498 beatificaciones vienen a juntarse a los 479 religiosos beatificados durante la dictadura.

48. Bedoya Juan G. La asociación de la memoria reclama que la iglesia perdone y pida perdón. In El País. El País.es. [En línea]. El País, el 28 de octubre de 2007 [Pagina consultada el 30 de octubre de 2007]. Disponibilidad en:

http://www.elpais.com/articulo/sociedad/Asociacion/Memoria/reclama/Iglesia/perdone/ pida/perdon/elpepusoc/20071028elpepisoc_6/Tes 
sigue profundamente dividida sobre la interpretación de su historia y sobre las políticas públicas que deben aplicarse para afrontarla. Sean cuales sean, la forma que esas políticas de la memoria toman y los procesos específicos que suponen, refuerzan o dan lugar a procesos de memorias rotas y fragmentadas a veces silenciosas y a veces combativas. Se dan así diferentes interpretaciones históricas del pasado y se abren debates públicos a menudo conflictivos en los cuales intervienen varios actores políticos y sociales que buscan influir el poder en un sentido u otro, dependiendo de sus intereses, bien para denunciar una memoria oficial que según ellos no ofrece una visibilidad pública satisfactoria, bien para convertirse en "vectores de la memoria» ${ }^{49}$. En Espańa, la memoria colectiva de la guerra civil y del franquismo ha llegado a ser, sin duda, un punto altamente neurálgico en los debates políticos y democráticos. Es efectivamente en esta pareja "memoria-democracia» donde parece ser que se han visto reflejadas las divisiones históricas e ideológicas entre franquistas y republicanos, convertidas ahora en espacio de luchas políticas y sociales del presente.

A través de estos conflictos de memoria se abre un debate sobre la naturaleza de la democracia española. Para avanzar en este camino tan delicado dos elementos que se dan pocas veces como evidentes, y mucho menos irremediablemente ligados, parecen incontrovertibles. En primer lugar, la voluntad de los gobiernos y las autoridades políticas de establecer criterios formales de condena histórica del pasado a través de la memoria. En segundo lugar, el establecimiento de un contexto propicio para la atenuación de las actitudes de exclusión entre los actores sociales y políticos en conflicto. Por tanto, ¿̨no es necesario y legítimo reconocer política y oficialmente el delito y la culpabilidad del Estado en una sociedad que se quiere democrática? ¿Una evaluación seria y objetiva del régimen de Franco no debe dar lugar a una condena inequívoca de todos los partidos políticos? ¿En algunos gestos de oposición no hay tentativas de borrar el pasado? ¿Puede un verdadero reconocimiento de los hechos históricos limitarse simplemente a la eliminación de símbolos aún presentes en lugares públicos? Más allá de las posibles respuestas a estas preguntas, parece que la reescritura de la historia de tres años de guerra civil impuesta por la dictadura franquista ha alcanzado sus objetivos: disolver los lazos de la memoria de vida común que unen a los miembros de una población. Significativamente, en 2010 España se ve sacudida por la acusación de "prevaricación» del juez Garzón por haber investigado sobre el traumático pasado franquista. En el momento de terminar este articulo, el panegírico de Franco que contiene el nuevo «Diccionario Biográfico Español» auspiciado por la Real Academia de la Historia obliga a historiadores del calibre de Julián Casanova o Santos Juliá a poner el grito en el cielo para denunciar la falta de honradez intelectual del proyecto.

49. Por «Vectores de la memoria» se entiende el conjunto de instrumentos vocación ideológica, pedagógica y unificadora, es decir, políticas memoriales generadas por instituciones con el objetivo de conservar, valorizar y transmitir el recuerdo de algunos aspectos del pasado considerados como particularmente significativos en la historia de un país. 